\title{
JUSTICIA RESTAURATIVA Y PROCESO PENAL GARANTÍAS PROCESALES: LÍMITES Y POSIBILIDADES*
}

\author{
RESTORATIVE JUSTICE AND CRIMINAL JUSTICE \\ PROCEDURAL SAFEGUARDS: LIMITS AND POSSIBILITIES
}

\author{
Alejandra Mera González-Ballesteros**
}

\begin{abstract}
RESUMEN
Hace ya más de tres décadas que se han venido implementando en diversas jurisdicciones programas de justicia restaurativa en el ámbito de la justicia penal, especialmente en los sistemas de justicia penal juvenil, ofreciendo una alternativa de resolución orientada a la reparación, desjudicialización y el diálogo entre los directamente involucrados en el conflicto. Este vertiginoso desarrollo ha precedido generalmente a la regulación legal y al debate sobre estándares y garantías procesales que deben orientar estos programas. Sin embargo, a medida que los programas de justicia restaurativa han ganado terreno y se han propuesto como mecanismos de resolución en casos de mayor gravedad y de criminalidad adulta, la necesidad de establecer estándares legales se ha hecho urgente. Hasta ahora, a nivel comparado, no existe acuerdo sobre la necesidad o el contenido de las garantías procesales aplicables a los programas de justicia restaurativa. Este trabajo propone que es necesario establecer estándares procesales claros en la implementación de estos programas, pero a su vez, que ellos deben adecuarse a los principios y fines que ésta persigue.
\end{abstract} en Ciencias Jurídicas y Sociales Universidad de Chile. Magíster en Justicia Criminal y Derechos Humanos, Universidad de Queen's, Belfast, Irlanda del Norte. Candidata a Doctora en Criminología, Universidad de Cambridge, Inglaterra. Correo electrónico: alejandra.mera@ mail.udp.cl 


\begin{abstract}
Since more than thirty years, many countries have implemented restorative justice programmes to deal with criminal matters, especially with young offenders. This programmes offer different ways to deal with the aftermaths of a crime, through diversion, reparation and the active participation of those involved in the conflict. This dramatic development has occurred, though, without broad legal regulations or deep debates regarding procedural safeguards and standards. Nevertheless, as restorative justice programmes grow and are being used to deal with serious offences and adult offenders, the need for the setting of safeguards is pressing. Until now, there is not agreement in the literature regarding the specific content of procedural safeguards for restorative justice. This paper suggests that procedural safeguards for restorative justice programmes are needed. But also proposes that these standards should respect restorative justice principles and aims.
\end{abstract}

\title{
PALABRAS CLAVES
}

Justicia Restaurativa; Garantías Procesales; Proceso Penal

KEY-WORDS

Restorative Justice; Procedural Safeguards; Criminal Justice.

\section{Introducción}

Intentar explicar qué es la justicia restaurativa no es una tarea fácil y no solamente porque bajo este concepto se agrupan diferentes procesos e intervenciones, sino porque además los objetivos, alcances e incluso los fundamentos de los diferentes programas denominados 'restaurativos' pueden ser considerablemente diversos. Por otra parte, los programas de justicia restaurativa no se restringen al área de la justicia penal. Así, programas de justicia restaurativa se han implementado, a nivel comparado, en conflictos civiles, disputas laborales, estudiantiles, conflictos comunitarios, etc. John Braithwaite, uno de los más influyentes promotores del movimiento de justicia restaurativa, señala que ésta "conlleva transformaciones radicales...no es una simple reforma al sistema de justicia criminal, sino una manera de transformar todo el sistema legal, nuestra vida familiar, nuestra conducta en el trabajo, nuestra forma de hacer política"1 2 .

Este trabajo no pretende analizar ni discutir si la justicia restaurativa vaya a transformar

Braithwaite, J (2003) "Restorative Justice and a better future" en Johnstone, G. (ed), A Restorative Justice Reader Texts, sources, context. Devon, Inglaterra: Willan Publishing. p.88.

Ésta, como todas las traducciones del inglés al español en este artículo, son mías. 
Justicia restaurativa y proceso penal garantías procesales: límites y posibilidades

Restorative justice and criminal justice procedural safeguards: limits and possibilities

nuestras prácticas políticas o sociales. Mi interés es describir el surgimiento del movimiento como una 'nueva manera' de enfrentar las consecuencias de los conflictos penales, en contraposición a la forma 'tradicional' ofrecida por nuestros sistemas de justicia, e intentar responder preguntas que la implementación de estos programas generan desde el punto de vista de los estándares que estos deben seguir para garantizar los derechos de las partes involucradas, especialmente de los imputados.

En la actualidad, la mayoría de los programas de justicia restaurativa han sido implementados en el terreno de la justicia penal juvenil, especialmente en casos de criminalidad leve o mediana, como una alternativa a la persecución. De este modo, los programas restaurativos se han mantenido generalmente en los márgenes del sistema y el debate sobre la necesidad de contar con estándares detallados de implementación no ha constituido una prioridad. C o m o señala Walgrave "Hasta ahora, la mayoría de las prácticas restaurativas se encuentran localizadas en una especie de isla dentro del sistema de justicia tradicional, donde excepcionalmente no se implementan sus apriorismos, o al menos éstos son susceptibles de ser modificados" ${ }^{3}$.

Con el tiempo, sin embargo, los programas de justicia restaurativa se han expandido al terreno de la justicia penal de adultos, como también a delitos de mayor gravedad y en algunas jurisdicciones constituyen la primera (o la más relevante) intervención disponible que el sistema de justicia penal ofrece para la resolución del conflicto, como se verá más adelante. En este caso, cuando los programas de justicia restaurativa pretenden desempeñar un rol central dentro del sistema de justicia criminal, las preguntas sobre hasta qué punto estos nuevos procesos se acomodan a los principios, objetivos y regulaciones del sistema de justicia tradicional, como el debido proceso, deben ser abordadas.

La expansión de los programas de justicia restaurativa y el debate sobre la necesidad de establecer estándares para su implementación han levantado interesantes preguntas relativas a la compatibilidad de estos programas con normas internacionales relativas al debido proceso. Más aún, han cuestionado la preponderancia de las garantías establecidas en favor de los imputados en los procesos de justicia criminal convencionales.

Quienes promueven la implementación de programas de justicia restaurativa señalan reiteradamente que el modelo representa una alternativa a la justicia tradicional. En este mismo sentido, el Consejo de Europa ${ }^{4}$ ha señalado que el movimiento surgió justamente desafiando

Walgrave, L. (2002) "Introduction" en Walgrave, L. (ed) Restorative Justice and the Law, Devon, Inglaterra: Willan Publishing. p. xvi.

Recomendación Nº (99) 19, 'Mediación en Materia Penal', adoptada por el Consejo de Ministros del Consejo de Europa el 15 de Septiembre de 1999. 
la aproximación tradicional del sistema legal. Si esto es así, entonces la justicia restaurativa ofrece un escenario diferente para las partes involucradas en un conflicto penal y tanto el contenido de los derechos de los ciudadanos para protegerse frente a la acusación, como el de los derechos de las víctimas durante el proceso están abiertos a ser revisados.

Ello no implica afirmar que estos programas no deben ser objeto de ninguna regulación o que no deban orientarse de acuerdo a determinados estándares con el fin de garantizar un justo proceso para todas las partes involucradas. Los procesos de justicia criminal, en cualquiera de sus versiones, constituyen una poderosa arma de control social que necesita ser regulada. Más aún, la mayoría de las veces tras un proceso restaurativo se imponen obligaciones que deben ser cumplidas por el ofensor y en caso de incumplimiento o desacuerdo, el caso vuelve generalmente a ser tratado en el sistema de justicia criminal tradicional. Esta situación impone la necesidad de establecer salvaguardas, tanto para la víctima como para el ofensor. El asunto es resolver qué tipo de estándares deben primar, si aquellos que incorporan las especificidades de los procesos restaurativos o bien aquellos que por estar pensados en otro esquema, hacen imposible que los programas restaurativos puedan lograr sus objetivos.

Walgrave argumenta que "Las garantías legales contenidas en el sistema de justicia penal tradicional no pueden ser simplemente trasplantadas. La justicia restaurativa reclama tener sus bases en una concepción de sociedad diferente y ofrecer un nuevo paradigma de justicia... El debido proceso, el derecho a defensa, culpabilidad y responsabilidad, proporcionalidad y otros principios siguen teniendo validez, pero su contenido debe ser revisado críticamente en el contexto de la justicia restaurativa, posiblemente reformulados, rechazados o reemplazados" ${ }^{5}$.

Este trabajo avanza justamente, en su segunda parte, en la revisión de ciertas garantías del debido proceso en relación a su interpretación en el contexto de programas restaurativos. No se hace una revisión exhaustiva de todos los elementos del debido proceso legal, sino se intenta avanzar una mirada crítica de ciertas garantías en orden a indagar en términos más precisos cuáles son las compatibilidades e incompatibilidades entre los estándares tradicionales de justicia criminal y los programas restaurativos.

En primer término, sin embargo, se aborda brevemente el nacimiento y expansión de los programas de justicia restaurativa y se describen las características más relevantes de los mismos.

Walgrave, Restorative Justice, cit. nota n.3, p.216. 
Justicia restaurativa y proceso penal garantías procesales: límites y posibilidades

Restorative justice and criminal justice procedural safeguards: limits and possibilities

\section{Origen, expansión y perspectivas de la Justicia Restaurativa}

\section{Nacimiento y expansión de la Justicia Restaurativa}

El Movimiento de justicia restaurativa en el marco de la justicia criminal emergió hace cerca de 30 años, básicamente como una crítica al sistema de justicia tradicional. Ontario, Canadá, es el lugar donde la literatura frecuentemente sitúa la primera experiencia de justicia restaurativa, cuando en 1974 el Mennonite Central Committee (Church), en el espacio brindado por ciertos tribunales, introdujo la mediación penal para resolver algunos casos. Desde entonces, se han implementado una gran cantidad de programas restaurativos en diferentes jurisdicciones, aunque existen diferencias relevantes entre los mismos.

A pesar de lo dicho anteriormente, muchos partidarios de la justicia restaurativa sostienen que las raíces de este tipo de procedimientos son más remotas y las sitúan en los sistemas de resolución de conflictos de las sociedades pre modernas. Sin embargo, esta aproximación ha sido discutida incluso por otros partidarios del movimiento. Como señala Dignan "Quienes sostienen que los mismos principios y prácticas fueron universalmente implementados por las sociedades pre modernas han exagerado y selectivamente interpretado la evidencia antropológica disponible" 6 .

Incluso el vínculo más frecuentemente citado entre justicia restaurativa y prácticas de justicia indígena, las Family Group Conferences $(F G C)$ de Nueva Zelanda y el sistema de justicia criminal Maorí, no es rigurosa. Así, aunque es cierto que el cuestionamiento Maorí al sistema de justicia criminal Neozelandés fue un ingrediente central de la reforma de $1989^{7}$, eso no significa que las conferencias restaurativas constituyan una práctica de justicia indígena. Las conferencias ofrecen, más bien, un modelo lo suficientemente flexible que puede adecuarse a los intereses y valores de las diferentes culturas involucradas.

Por las razones recién expuestas, la justicia restaurativa puede caracterizarse mejor como un movimiento nuevo, que lejos de ser unívoco, reúne diferentes tendencias. Dada la variedad de programas que se agrupan bajo la 'etiqueta' de restaurativos, no es extraño que las definiciones del concepto también varíen.

La definición más ampliamente reproducida de justicia restaurativa corresponde a Marshall, para quien "La justicia restaurativa es un proceso a través del cual las partes que se han visto involucradas en un delito resuelven de manera colectiva la forma cómo lidiar con las

\footnotetext{
6 Dignan, J. (2005) Understanding Victims and Restorative Justice, Maidenhead, Inglaterra: Open University Press. p.94.

Más adelante en este artículo se explica con más detalle el sistema restaurativo Neozelandés.
} 
consecuencias inmediatas de éste y sus repercusiones para el futuro" (en Gavrielides, 2007²)

Esta definición, sin embargo, presenta algunos problemas. Por ejemplo, como señala Braithwaite $^{9}$, su mayor limitación es que no señala qué es lo que tiene que ser restaurado y no define los valores de la justicia restaurativa. Por otra parte esta definición es estrecha porque sólo incluye encuentros cara a cara y enfatiza el proceso por sobre el objetivo principal que es reparar el daño causado por el ofensor.

La definición contenida en los 'Principios Básicos sobre el uso de programas de justicia restaurativa en materia criminal' (en adelante, Principios Básicos), del Consejo Económico y Social de las Naciones Unidas del año 2002 parece ser más completa. Así, ésta define a los programas de justicia restaurativa como "cualquier programa que usa procesos restaurativos y busca lograr resultados restaurativos". Por procesos restaurativos la Declaración entiende "cualquier proceso en el cual la víctima y el ofensor, y cuando es apropiado otras personas o miembros de sus comunidades afectados por el delito, participan juntos activamente en la resolución de los problemas generados por el delito cometido, generalmente con la ayuda de un facilitador. Estos procesos pueden incluir mediación, conciliación, conferencias y círculos de sentencia." Por su parte, los resultados restaurativos consisten en los acuerdos logrados como resultado de un proceso restaurativo. Incluyen respuestas y programas como la reparación, restitución o servicio a la comunidad, con el objeto de satisfacer necesidades y responsabilidades de las partes y de la comunidad y lograr la reintegración de la víctima y ofensor ${ }^{10}$.

Debido a la variedad de programas de justicia restaurativa se hace difícil dar con una definición completamente satisfactoria, por lo tanto quizá es orientador entender cuáles son los fundamentos políticos, intelectuales y filosóficos del movimiento.

Dignan $^{11}$ identifica tres corrientes principales: la tesis 'civilizatoria', la tesis 'comunitarista' y la tesis del 'discurso moral'. Así, en primer término, la justicia restaurativa se fundamentaría en una profunda crítica al sistema de justicia criminal tradicional. En este sentido Braithwaite, quien señala que "Pocos diseños institucionales creados desde la revolución industrial en los países occidentales han sido tan fallidos como el sistema de justicia criminal. En teoría, este administra justicia, proporciona castigos y previene la comisión de delitos. En la práctica, falla castigando y previniendo casi tan a menudo como empeora las cosas... todos los sistemas de

Gavrielides, T. (2007) Restorative Justice Theory and Practice: Addressing the discrepancy, Helsinki, European Institute for Crime Prevention and Control (HEVNI), Publication Series 52.

9 Braithwaite, J. (2002) Restorative Justice and Responsive Regulation. Oxford, Inglaterra: Oxford University Press. p. 3.

10 "Principios Básicos sobre la utilización de Programas de Justicia Restaurativa en Materia Penal" (2002) ECOSOC, I. $1,2,3$.

11 Dignan, Understanding, cit. nota n.6. 
Justicia restaurativa y proceso penal garantías procesales: límites y posibilidades

Restorative justice and criminal justice procedural safeguards: limits and possibilities

justicia criminal occidentales son brutales, institucionalmente vengativos y deshonestos al declarar sus intenciones"12.

Desde esta perspectiva, según Dignan, la justicia restaurativa es vista como una manera de 'civilizar' el "barbárico juego de crimen y castigo" que rige en la actualidad ${ }^{13}$, poniendo mayor atención en la reparación del daño a favor de las víctimas.

Otro enfoque de esta tesis se asocia con el movimiento cristiano menonita, que busca poner énfasis en los valores de reconciliación y reparación. El objetivo es que víctima y ofensor se encuentren y hablen sobre el delito, generalmente en el formato de un programa de mediación de carácter informal.

La segunda tesis, o tesis 'comunitarista', se funda en la crítica al sistema de justicia tradicional en cuanto éste entiende a la ofensa criminal como un acto individual del ofensor en contra del estado, por lo que en términos generales los intereses de las víctimas y la comunidad quedan excluidos del proceso. El comunitarismo demanda la inclusión de la víctima, pero de manera más importante, la inclusión de los intereses de la comunidad en el proceso de toma de decisiones. Desde esta perspectiva, al concentrarse solamente en las relaciones interpersonales entre la víctima y el ofensor, el sistema de justicia criminal no toma suficientemente en consideración las implicancias sociales y morales del delito. La tesis comunitaria en el ámbito de la justicia criminal ha sido fuertemente influenciada por el trabajo de Niels Christie. Su artículo 'Conflictos como pertenencia', publicado en 1977, es hoy un clásico, citado en muchos de los trabajos académicos sobre justicia restaurativa. Particularmente relevante en esta ámbito resulta el ethos anti estatal de la postura de Christie, como el interés por procesos informales, alejados de la intervención profesional de abogados y otros agentes judiciales ${ }^{14}$.

Ahora bien, el concepto, ámbito y rol que juega la comunidad en los procesos restaurativos es variado y discutido entre las diferentes tendencias dentro del movimiento.

Finalmente, un tercer fundamento que puede identificarse en el plano de la teoría de la justicia restaurativa es el denominado 'discurso moral'. Uno de los más renombrados exponentes de esta tendencia es John Braithwaite y su teoría sobre la 'vergüenza reintegradora' (reintegrative shaming) Esta tesis descansa en el reconocimiento de que la conciencia es generalmente una herramienta más poderosa para controlar el delito que el castigo. Braithwaite sostiene que el crimen debe ser enfrentado, pero de una manera que no estigmatice negativamente al ofensor. Su teoría señala que la tolerancia frente al crimen no resuelve el problema, pero la 'vergüenza

Braithwaite, Restorative Justice and a Better, cit. nota n.1, pp. 85-86.

Dignan, Understanding, cit. nota n.6. p. 96.

Christie, N. (1977) "Conflicts as Property" British Journal of Criminology Vol. (17), pp. 1-15. 
irrespetuosa', como es usada en el sistema de justicia criminal tradicional, hace que la situación empeore, pues genera una estigmatización permanente ${ }^{15}$. Al contrario, si el ofensor es ‘avergonzado' por lo que ha hecho, pero de una manera respetuosa y en presencia de la víctima y de personas que son importantes para él, es más probable que enfrente la ofensa, acepte su responsabilidad y cambie su conducta. Así, Braithwaite señala que "El sistema de justicia funcionará mejor cuando facilite el razonamiento moral de las familias en cuanto a qué hacer con el crimen como una alternativa al castigo estatal... No es la vergüenza infringida por un policía, un juez o la prensa la que nos hace comprender; es la vergüenza en los ojos de quienes respetamos y confiamos"16. La tesis de Braithwaite ha sido muy influyente en la implementación de proyectos de justicia restaurativa con base en la policía en Australia y el Reino Unido.

Estas tendencias de pensamiento han informado y motivado la implementación y desarrollo de diferentes programas restaurativos en diversos países, especialmente en sistemas de common law como Australia, Nueva Zelanda, el Reino Unido, Canadá y Estados Unidos. Programas de mediación y conciliación, sin embargo, están presentes en la mayoría de los países europeos, particularmente en los sistemas de justicia penal juvenil. Sin embargo, las características de estos programas difieren dependiendo de la etapa del procedimiento en la cual tienen lugar (por ejemplo, si se emplean como alternativas al proceso o 'diversión', antes de la sentencia, post-sentencia, etc.), el tipo de ofensores y ofensas que pueden ser susceptibles de acceder a un programa restaurativo (jóvenes, adultos, ofensas menores, delitos graves, etc.), o bien el modelo de programa implementado (mediación, conferencias, círculos, etc.)

Más allá de las diferencias y complejidades de cada modelo, puede señalarse que siempre existen al menos dos aspectos compartidos: todos intentan reparar el daño causado por la comisión del delito y todos se orientan a que el ofensor enfrente su responsabilidad frente a las personas que han sido afectadas por sus actos ${ }^{17}$. Muchos de ellos, en especial aquellos que han sido caracterizados como 'más' restaurativos, comparten además el compromiso con establecer encuentros informales, inclusivos y no coercitivos.

\section{Programas de Justicia Restaurativa}

Como ya se ha adelantado, existe gran variedad de programas de justicia denominados 'restaurativos', como por ejemplo, la mediación víctima-ofensor, la conciliación, los círculos de sentencia, paneles de justicia juvenil, conferencias restaurativas, etc. En lo que sigue se describirán con algún detalle dos de estos modelos: las Conferencias Familiares (Family Group Conferences, FGC en adelante) de Nueva Zelanda, por ser uno de los sistemas más

\footnotetext{
15 Braithwaite, Restorative Justice and a Better, cit. nota n.1

16 Braithwaite, Restorative Justice and Responsive, cit. nota n.9, p. 74.

17 Dignan, Understanding, cit. nota n.6.
} 
Justicia restaurativa y proceso penal garantías procesales: límites y posibilidades

Restorative justice and criminal justice procedural safeguards: limits and possibilities

característicos del movimiento y la mediación penal, por ser quizá el modelo más extendido.

Mediante la 'New Zealand's Children, Young Persons and their Families Act' de 1989, Nueva Zelanda reformó de manera radical sus sistema de justicia juvenil. Esta reforma estuvo motivada fundamentalmente en la crítica del pueblo Maorí al sistema tradicional, en la presión ejercida por el movimiento de apoyo a los derechos de las víctimas y en los generalizados altos grados de insatisfacción con el sistema de justicia juvenil (excesiva institucionalización, malos tratos, etc.) El nuevo sistema intentó superar las dicotomías del modelo de bienestar y de justicia, haciendo responsable al niño, pero a la vez entregándole la consideración necesaria a sus necesidades ${ }^{18}$.

La pieza central del nuevo sistema son las $F G C$, pues aunque no son utilizadas en todos los casos, brindan un modelo de conducción para todas las etapas del proceso. La idea es que la policía tome medidas leves siempre cuando sea posible, de manera más o menos informal. Si la ofensa no es suficientemente seria, la policía termina el asunto en la calle o con una advertencia inmediata. Si es necesario tomar otra medida se deriva al joven a la Sección Policial de Ayuda a la Juventud, la que en presencia de los padres le entrega una advertencia, pide una disculpa para la víctima o le impone una sanción adicional, con su consentimiento (por ejemplo, un trabajo comunitario) Estas formas de término ocurren en cerca del $70 \%$ de los casos. Sólo cuando las advertencias no han sido exitosas en el pasado o cuando la ofensa es más seria, se deriva al joven a una $F G C$. Si el joven es arrestado se envía el caso directamente a la Corte Juvenil, pero ello ocurre sólo en casos graves.

Existen dos maneras de derivar a un joven a una $F G C$. En primer lugar, mediante la Sección de Ayuda a la Juventud, cuando se considera que el caso sería lo suficientemente relevante para ser conocido en la Corte. El joven debe aceptar participar. Si niega los cargos, la Sección puede solucionar informalmente el caso o enviarlo a la Corte, dependiendo de las circunstancias del delito. Si es enviado a la Conferencia y es exitosa, se da por finalizado el conflicto. En segundo término, el caso puede ser derivado por la Corte Juvenil. Aquí, los resultados se envían al juez para ser tomados en cuenta en la sentencia. La Corte puede enviar al joven cuando 'no niega' los cargos. También puede ser enviado si los cargos se prueban, pero no ha habido oportunidad previa para considerar la mejor forma de enfrentar el conflicto y parece necesario o deseable hacerlo.

Luego de la derivación, un Coordinador de Justicia Juvenil (funcionario estatal) debe

18 Morris, A., y Maxwell, G. (2003) "Restorative justice in New Zealand: family group conferences as a case study" en Johnstone, G. (ed), A Restorative Justice Reader Texts, sources, context. Devon, Inglaterra: Willan Publishing. 
encargarse de toda la organización de la Conferencia, asegurando que los objetivos y principios de la ley se cumplan.

En la Conferencia deben estar presentes el joven, un familiar, el coordinador, la víctima o un representante, un representante de la policía, un abogado del joven si ha sido derivado por la Corte (a veces incluso cuando no es derivado por la Corte, pero no es muy común) y un trabajador social cuando el niño está en una institución. Otras personas significativas para ambas partes también pueden asistir si así lo desean.

El proceso es flexible, pues la idea es justamente que la familia determine cómo llevar adelante la conferencia, aunque la práctica ha desarrollado algunas rutinas que marcan un patrón de proceso. Generalmente se arregla el lugar con cómodas sillas en círculo. El coordinador comienza dando la bienvenida a los participantes, presentándolos y describiendo en términos generales los propósitos del encuentro. Luego, usualmente el policía lee un resumen con los hechos relevantes y se le pregunta al joven si está de acuerdo con la exposición. Como no se requiere una aceptación de culpabilidad formal para mandarlo a la Conferencia, sólo es necesario que no niegue los cargos. Pueden surgir desacuerdos en este punto, especialmente con la víctima. Si el desacuerdo persiste, se manda el caso de vuelta a la Corte o a la policía (dependiendo de quién hizo la derivación) Luego, la víctima o su representante describen los efectos que el delito le ha causado y cómo se sienten respecto de lo que pasó. Esto es muy relevante para la víctima, pero para el joven también, pues le da un claro entendimiento del impacto de lo que ha hecho, tomando mayor responsabilidad. Posteriormente hay una discusión abierta de la ofensa y de las circunstancias que la provocaron, tras lo cual el joven y su familia dejan la sala para discutir un plan que contenga una propuesta de reparación del daño y condiciones para prevenir la reincidencia. Esta es una reunión privada que demuestra el compromiso de la ley de hacer protagonista a las familias. Después de esta reunión, que dura al menos media hora, vuelven a la sala. Un vocero señala cuál es el plan y se discute la propuesta. A veces en este momento la familia y el joven se disculpan con la víctima. Si se llega a un acuerdo, el proceso concluye ahí (aunque si el caso fue derivado por la Corte, el acuerdo debe ser aprobado por ésta o al menos debe orientar su decisión)

Central es que las partes envueltas directamente en el conflicto y no los profesionales que participen en la Conferencia sean quienes deben tomar las decisiones sobre qué hacer. Los acuerdos deben tomar en cuenta el punto de vista de la víctima, la necesidad de hacer responsable al joven por el delito y cualquier otra medida que pueda prevenir que éste reincida, aumentando su bienestar o fortaleciendo a la familia. El rango de posibles medidas es extenso y puede incluir una disculpa, trabajo comunitario, reparación, participación en un programa, supervisión, restitución, etc. Los acuerdos más comunes incluyen disculpas y trabajo comunitario. La reparación económica está presente en sólo un tercio de los acuerdos, dado el escaso nivel económico del joven, pero además porque a veces se entiende que no es necesaria o apropiada para el caso. 
Justicia restaurativa y proceso penal garantías procesales: límites y posibilidades

Restorative justice and criminal justice procedural safeguards: limits and possibilities

Las evaluaciones de este sistema indican que, en términos generales, las conferencias son vistas de manera positiva por todos los involucrados. Según la evaluación realizada por Maxwell y Morris $^{19}$ en 1990-1991, cerca de la mitad de los jóvenes se sintieron involucrados en el proceso de llegar a una decisión. Otra mitad sintió que su voluntad había sido subsumida por su familia, pero de acuerdo a Maxwell y Morris, incluso este porcentaje de involucramiento es mucho mayor al de los jóvenes en la Corte, donde generalmente permanecen pasivos, dejando actuar a sus abogados. En relación a los acuerdos, los jóvenes muestran altos niveles de satisfacción $(84,85 \%)$ De las víctimas que participaron, cerca del $60 \%$ describe la $F G C$ como de gran ayuda, positiva y reconfortante. Generalmente se sintieron activamente involucradas en el proceso y mejor tras haber participado, pudieron intervenir en el logro del acuerdo y además pudieron enfrentarse cara a cara, lo que les permitió comprender mejor lo que había pasado y enfrentar de mejor manera una situación similar en el futuro. Un cuarto, sin embargo, dijo sentirse peor, especialmente por sentir que el ofensor y su familia no sentían lo que había sucedido.

Por otra parte, la reincidencia tras un procedimiento restaurativo de estas características parece no ser peor, y a veces muestra mejores resultados que el sistema tradicional $^{20}$.

Ahora bien, en cuanto a la mediación penal, innumerables programas se han implementado, tanto en Europa como América. Aquí describiremos los aspectos generales de estos procesos, sin orientarnos a un programa específico. Existen innumerables versiones de mediación penal, pero aquí se describen dos modelos que contienen las características centrales de estos procesos: el modelo 'clásico' de mediación como reconciliación víctima-victimario y el modelo 'humanístico' o 'transformativo'.

El modelo 'clásico' intenta el acercamiento de las partes luego de un arduo trabajo preparatorio previo, con entrevistas individuales del mediador con ambas partes. Este análisis previo permite cerciorarse de que el caso es admisible para un programa de estas características y además las partes pueden resolver en este momento sus dudas y así ejercer una opción plenamente informada. Además, se establece una relación de seguridad y confianza con el mediador y este puede preparar adecuadamente a las partes para el encuentro.

Si ambas partes acceden a participar (y están en condiciones de hacerlo), se fija una reunión común. El ofensor debe aceptar que cometió el delito y mostrar algún grado de arrepentimiento. Dependiendo del programa, existen ciertos delitos que quedan excluidos de la posibilidad de ser resueltos mediante una mediación, generalmente los delitos graves o

Morris y Maxwell, Restorative Justice, cit. nota n.21.

Sherman, J. y Strang, H. (2007) "Restorative Justice: The Evidence" http://www.esmeefairbairn.org.uk/docs/ RJ_exec_summary.pdf. (visitado el 10.11.08) 
violentos, pero en principio no existen razones para excluir automáticamente determinadas situaciones, como han demostrado experiencias de mediación en delitos graves, violencia intrafamiliar, etc. En estos casos, sin embargo, el mediador debe estar especialmente entrenado para manejar estas situaciones, especialmente cuando hay desequilibrios de poder entre las partes.

Si se llega a un acuerdo, se acaba el caso ahí o se reenvía a los tribunales para algún tipo de aprobación o formalidad, según sea el caso. Otras veces es necesario tener uno o más encuentros posteriores para llegar a un acuerdo. El mediador generalmente debe vigilar el cumplimiento del acuerdo, solucionando inconvenientes que pudieran surgir posteriormente. Los acuerdos, al igual que las $F G C$, pueden ser variados y el marco legal varía de jurisdicción en jurisdicción.

En algunas oportunidades la mediación cara a cara no es posible y los mediadores sirven de puente entre víctima y ofensor, facilitando un diálogo entre ambos, pero sin que se produzca un encuentro. Esta mediación se ha denominado 'indirecta'. Como se entiende, este proceso constituye un modelo muy pobre de mediación de acuerdo a las características, fines y principios de la justicia restaurativa y en lo posible debería restringirse a casos muy limitados, cuando el encuentro se hace extraordinariamente difícil.

El modelo ‘transformativo' va más allá que el modelo clásico y busca brindar a las partes la oportunidad de hablar recíprocamente, de permitir que las víctimas expresen el impacto del crimen y recibir respuestas a interrogantes importantes. La indemnización es relevante, pero secundaria. La preparación previa y por separado es fundamental, poniéndose el énfasis en expresar cómo el crimen las ha afectado, identificando sus necesidades y preparándolas para la mediación. El mediador, por último, tiene un estilo más cercano a un 'facilitador', tratando de intervenir lo menos posible en el proceso de toma de decisiones. Estas características hacen que este tipo de mediación cumpla de mejor manera con los objetivos declarados del movimiento de justicia restaurativa.

El momento y efecto que el acuerdo de mediación tiene varía según la jurisdicción, pero muchas veces sustituye a la persecución o la sentencia.

\section{Expansión y futuro de la Justicia Restaurativa}

El dramático crecimiento y expansión del movimiento de justicia restaurativa en el ámbito criminal se ha visto asociado a programas que se relacionan con criminalidad leve, especialmente en el ámbito de la justicia penal juvenil. 'Sacar' a los niños, particularmente si son autores de delitos leves, del sistema de justicia criminal ha sido visto como una buena estrategia para enfrentar estos conflictos, especialmente para prevenir el comienzo de una carrera criminal. Como señala Hudson "Los jóvenes infractores necesitan desarrollarse en un ambiente alejado 
Justicia restaurativa y proceso penal garantías procesales: límites y posibilidades

Restorative justice and criminal justice procedural safeguards: limits and possibilities

del delito, lejos del castigo y la estigmatización que restringe sus posibilidades de vincularse a otros jóvenes que no delinquen, de encontrar empleo y de asumir responsabilidades familiares y ciudadanas ${ }^{21} "$.

El fracaso del sistema de justicia criminal a lo largo de la historia para abordar el problema de la criminalidad juvenil es evidente. El hecho de que gobiernos y políticos estén permanentemente innovando y proponiendo nuevas 'panaceas' para manejar el conflicto y la constante demanda de los instrumentos internacionales de derechos humanos por 'alternativas' para los jóvenes ofensores son finalmente señales de ello. La cárcel y otras respuestas del sistema penal no han sido ineficaces solamente para disminuir la reincidencia, sino que en muchas ocasiones son un factor que la aumenta.

Por el contrario, evaluaciones de programas que usan la aproximación restaurativa, a la vez de mostrar altos niveles de satisfacción de las partes involucradas, también han registrado impactos en la disminución de la reincidencia ${ }^{22}$. El sistema de justicia criminal tradicional simplemente no puede mostrar los mismos resultados, tanto en el modelo de protección o bienestar, como en el de responsabilidad.

Este contexto hace más fácil entender por qué, cuando se trata de jóvenes infractores, las últimas décadas han sido testigos de una creciente aceptación de los beneficios de los mecanismos alternativos en general y de los programas restaurativos en particular. No es sorprendente, en consecuencia, que muchos instrumentos de derechos humanos relativos a justicia juvenil reclamen flexibilidad, diversión, alternativas a la institucionalización, etc., todos ellos aspectos claves de la justicia restaurativa ${ }^{23}$. Pero no sólo los instrumentos internacionales han dado la bienvenida a este tipo de procedimientos. Legislaciones nacionales en varios países también han reformado sus procesos con esta orientación.

Quizá la legislación más representativa en la materia es la legislación Neozelandesa introducida el año 1989, como ya se ha hecho referencia. Pero esta no es la única. Un camino similar ha emprendido recientemente Irlanda del Norte desde el año 2002, luego de la implementación de la normativa 'Justice (Northern Ireland) Act', legislación mediante la cual se introdujo el Servicio Juvenil de Conferencias (Youth Conferencing Service) Asimismo, Inglaterra y el resto de Europa han implementado algunas medidas restaurativas, aunque

21 Hudson, B. (2002) “Justice and Gendered Violence. Diversion or Effective Justice?” British Journal of Criminology, Vol. (42) p. 618

22 Ver, por ejemplo, Johnstone, G. (ed), A Restorative Justice Reader Texts, sources, context. Devon, UK: Willan Publishing; Sherman y Strang, "Restorative", cit. nota n.23.

23 Por ejemplo la Convención Internacional sobre los Derechos del Niño, las Reglas Mínimas de las Naciones Unidas para la Administración de Justicia de Menores, o 'Reglas de Beijing', etc. 
ciertamente con menos fuerza que los casos de Nueva Zelanda e Irlanda del Norte. Aquí, además, estos programas coexisten con otras medidas que son altamente duras y represivas. Por ello, Gelsthorpe y Morris han argumentado que los elementos restaurativos en Inglaterra son parciales y periféricos y se preguntan si acaso la justicia restaurativa es suficientemente nueva y radical para revitalizar la justicia juvenil en Inglaterra y Gales. Para ellas, a pesar de las buenas intenciones "El peso de la justicia restaurativa permanecerá tenue a menos que los valores contradictorios y en competencia presentes en la política criminal juvenil de Inglaterra y Gales en general, y la legislación de 1998 en particular, le conceda mayor espacio" ${ }^{24}$.

Por otra parte, la pretensión del movimiento de justicia restaurativa de reformar o reemplazar el sistema de justicia criminal tradicional debe ser puesta en contexto. El desarrollo y crecimiento de estos programas tienen sus limitaciones. Por muchas razones, es más factible que estos programas coexistan con el sistema de justicia criminal convencional antes que lo reemplacen. Incluso Braithwaite, uno de los partidarios más apasionados del movimiento, sostiene que las intervenciones restaurativas deberían ser aplicadas de acuerdo a una pirámide regulatoria. La idea es que en general la primera reacción frente al delito debiera ser restaurativa, de diálogo, y luego, si es estrictamente necesario, se podría intervenir de una manera más punitiva. La pirámide, sin embargo, es un modelo dinámico. Como señala Braithwaite "No se trata de especificar por adelantado cuáles son los tipos de conflictos que deberían estar en la base de la pirámide, cuáles son más serios y deberían fijarse en el centro y cuáles, por ser los más graves, deberían estar el tope... la presunción debería ser que, no obstante la seriedad del delito, la respuesta normal es intentar el diálogo primero para luego desechar esta modalidad sólo si hay razones de peso para hacerlo" 25 .

Otra limitación importante de los programas de justicia restaurativa se encuentra en el hecho de que estos no pueden ser obligatorios. Por el contrario, ellos necesitan contar con el consentimiento del ofensor (a veces también de la víctima) para ser llevados adelante. Más aún, requieren que el ofensor no niegue, o bien acepte, responsabilidad en el delito. De esta forma, en todos los casos en que el ofensor niega su responsabilidad, la justicia criminal convencional retiene su tarea determinar si el delito fue cometido y en caso afirmativo, establecer si el imputado es o no responsable.

Por ahora y ciertamente por el futuro cercano la justicia restaurativa ocupará en términos generales un espacio, mayor o menor de acuerdo a las circunstancias específicas del contexto, dentro del sistema de justicia penal tradicional. Tanto por sus propias características, como se ha se ha visto, como por su incipiente desarrollo y las resistencias que generan este tipo de

\footnotetext{
24 Gelsthorpe, L. y Morris, A. (1999) "Much ado about nothing. A critical comment on key provisions relating to children in the Crime and Disorder Act 1998" Child and Family Lay Quarterly, 11 (209).

25

Braithwaite, Restorative Justice and Responsive, cit. nota n.9, p. 30.
} 
Justicia restaurativa y proceso penal garantías procesales: límites y posibilidades

Restorative justice and criminal justice procedural safeguards: limits and possibilities

procesos, el sistema penal servirá de telón de fondo en el escenario de las prácticas restaurativas, el que sin lugar a dudas permeará su dinámica y condicionará sus contenidos. Esta situación, desde mi punto de vista, no implica necesariamente que los programas restaurativos deban adecuarse absolutamente a las garantías procesales tradicionales como única forma de subsistir, pero tampoco que estos programas deban situarse al margen de la ley. Como señala Walgrave "El formalismo legal no debe inmiscuirse en los procesos restaurativos, pero el proceso debe desarrollarse dentro de un marco legal"26.

En síntesis, programas de justicia restaurativa han sido implementados en muchas jurisdicciones, con mayor o menor entusiasmo y han sido vistos como una mejor manera de resolver casos criminales relativamente leves, especialmente cuando el ofensor es un menor de edad ¿Pero cuál es la perspectiva de la justicia restaurativa cuando se trata de ofensores adultos y de criminalidad más grave? Aunque algunos programas han sido implementados en la justicia de adultos y para crímenes de mayor gravedad, estos están lejos de ser tan numerosos y atraer tal nivel de consenso como ocurre en la justicia juvenil. Existen muchos argumentos para limitar la implementación de programas de justicia restaurativa en este contexto. Uno de los más fuertes es quizá que estos programas contravienen garantías y derechos fundamentales de los involucrados en el conflicto penal, especialmente las garantías de los ofensores.

En lo que sigue, este trabajo discute justamente si es posible compatibilizar estándares clásicos del debido proceso con los requerimientos de programas restaurativos.

\section{Justicia Restaurativa: Garantías y Estándares}

\section{La necesidad de establecer estándares}

Dignan señala que muchas veces los procesos de justicia restaurativa, lejos de ser puramente simbólicos, terminan por imponer obligaciones que van más allá de la simple restitución. Así las cosas, levantan fundadas preocupaciones relativas a la equidad de estos procesos, como también de sus resultados. El autor agrega que estas circunstancias “... al menos llaman la atención sobre la necesidad de establecer estándares adecuados para las víctimas y ofensores. Pero también la necesidad de que los partidarios de la justicia restaurativa reconozcan que las dudas y preocupaciones que muestran los escépticos, como por ejemplo las relativas a la proporcionalidad y equidad, son bien fundadas y necesitan ser confrontadas"27.

Generalmente uno de los objetivos de los programas de justicia restaurativa es acordar un plan para el ofensor, el que puede contener diferentes tipos de obligaciones, desde una disculpa

Walgrave, "Introduction", cit. nota n.3, p.xvi.

Dignan, Understanding, cit. nota n.6, p.3. 
hasta algún tipo de reparación, incluso el encarcelamiento en determinadas circunstancias. En este contexto, parece suficientemente claro la necesidad de establecer límites y garantías. Algunos, sin embargo, han argumentado que la necesidad de establecer estándares en estos procesos se atenúa puesto que la justicia restaurativa no impondría castigos ${ }^{28}$. Así, es común encontrar en la literatura sobre justicia restaurativa un contraste absoluto entre justicia retributiva y justicia restaurativa, donde, como señala Daly “todos los elementos asociados a 'lo bueno' (a una superior forma de justicia) están situados en la columna restaurativa, mientras que todos los asociados con 'lo malo' (o una forma inferior de justicia) están en la columna retributiva" 29 . Y de la misma manera en que estos elementos punitivos son desechados, también es desechada la necesidad de regular los procesos restaurativos y establecer mecanismos de protección para las partes.

Daly señala, sin embargo, que el concepto de 'retribución' en estos casos está incorrectamente asociado con una estrecha conceptualización del castigo, el que enfatiza las emociones de venganza y la intención de infligir dolor en el afectado. Pero ambos términos, 'retribución' y 'castigo', según Daly, pueden ser definidos en forma más amplia, incluso en términos compatibles con el acercamiento restaurativo y, por lo tanto, no sería correcto sostener que la justicia restaurativa no puede llegar a constituir un castigo. Más aún, Daly señala que por su propia experiencia evaluando Conferencias en Australia y Nueva Zelanda, éstas incorporan muchos elementos de la justicia retributiva (algunos de una perspectiva rehabilitadora) y muchos elementos restaurativos ${ }^{30}$. Duff, desde una perspectiva similar, señala que lo retributivo y lo restaurativo no están tan alejados como los partidarios de la justicia restaurativa frecuentemente creen, señalando que "una vez que se entiende que hay que restaurar en un contexto de una ofensa criminal... veremos que la restauración no es solamente compatible con la retribución y el castigo, sino que los requiere" 31 .

Pero incluso aunque no se comparta la idea de que a través de la justicia restaurativa se impone un castigo, la necesidad de establecer estándares de implementación podría fundarse en el hecho de que en una sociedad punitiva, cualquier tipo de intervención estatal tiene la potencialidad de ser infundada, excluyente y arbitraria.

Un segundo argumento enarbolado por los defensores de la justicia restaurativa para restringir la imposición de estándares es que estos serían contrarios a la 'informalidad' y 'flexibilidad' que reclaman los programas restaurativos. Pero incluso cuando es verdad que

Braithwaite, J. (2002) "Setting Standards for Restorative Justice", British Journal of Criminology (42) pp. 563-577 Daly, Daly, K. (2002) "Restorative Justice: the real story.” Punishment \& Society. 4; 55. p. 56.

Idem.

Duff, R. (2003) "Restorative punishment and punitive restoration" en Johnstone, G. (ed.) A Restorative Justice Reader. Texts, sources, context. Inglaterra: Willan Publishing, p.382. 
Justicia restaurativa y proceso penal garantías procesales: límites y posibilidades

Restorative justice and criminal justice procedural safeguards: limits and possibilities

estos procedimientos son más informales y deben ser más flexibles que los procedimientos tradicionales, ello no significa que no puedan o deban ser regulados. Como ha señalado la Recomendación (99)19 del Consejo de Europa sobre Mediación en materia criminal ${ }^{32}$, "La Mediación tiene un carácter menos formal que los procedimientos de justicia criminal, con el objeto de permitir una forma más personal y comprehensiva de aproximación al conflicto. Estos procesos, no pueden, ni deben, ser regulados en detalle. Sin embargo, hay derechos y salvaguardas procesales de los individuos en el proceso criminal que no pueden ser descartados en una sociedad gobernada por el estado de derecho" ${ }^{33}$.

De esta forma, la flexibilidad e informalidad de los procesos restaurativos debe ser tomada en cuenta a la hora de fijar los estándares que regirán la implementación de este tipo de programas, pero ello no significa que cualquier tipo de regulación sea contraria a los principios de la justicia restaurativa.

Finalmente, un tercer argumento esgrimido en contra de la necesidad de regular estándares reclama que ellos no son necesarios por la 'bondad intrínseca' de la justicia restaurativa. Este argumento, sin embargo, no resiste mayor análisis. Cuando se habla de justicia criminal, las buenas intenciones no son suficientes y la historia está llena de buenas intenciones seguidas de prácticas inaceptables, como lo demuestra, por ejemplo, el sistema proteccional para menores de edad que Chile se ha propuesto dejar atrás.

Por estas razones, la mayoría de los promotores de la justicia restaurativa coinciden en la necesidad de acordar estándares que aseguren la legitimidad de los procesos y algún grado de proporcionalidad de los resultados. La pregunta es, entonces, qué tipo de estándares son adecuados.

Parte de la complejidad que presenta esta pregunta, tal como han señalado Mc Evoy et al. ${ }^{34}$, se debe a las radicales diferencias de las filosofías de justicia que subyacen a las posturas que han liderado el debate sobre este punto. Así, entre la teoría del 'justo merecimiento'o 'proporcionalidad' (just deserts), que valora "las virtudes del debido proceso y la proporcionalidad por sobre cualquier otra consideración" y los promotores de la justicia restaurativa, quienes consideran estos principios a lo más como ideales incumplidos de un fallido sistema de justicia, ha tendido a primar un diálogo de sordos, impidiendo el debate.

Así las cosas, este trabajo intentará argumentar que la única forma de avanzar en esta

La Recomendación incluye en el término mediación una amplia gama de alternativas a la justicia penal tradicional, entre ellas la justicia restaurativa.

33 Explanatory Memorandum.

34 McEvoy, K., Mika, H. y Hudson, B. (2002) "Introduction: Practice, Performance and Prospects for Restorative Justice" British Journal of Criminology (42), pp. 469-475. 
discusión (y de paso en la implementación de programas de justicia restaurativa de manera más amplia) es establecer un puente entre ambas posturas. Esto es, los programas de justicia restaurativa tienen que sujetarse a ciertos estándares que garanticen el respeto de los derechos de los participantes, pero esos estándares deben ser compatibles con la filosofía y principios que subyacen a los programas de justicia restaurativa. Entre estos estándares, particular interés presentan los contenidos en instrumentos de derechos humanos en lo referido a los procesos de justicia criminal. Como señala Braithwaite, los instrumentos de derechos humanos de las Naciones Unidas, aunque sin dudas no son perfectos, representan "La decantación de décadas de deliberación durante las cuales todas las naciones han participado en la construcción de fundamentos consensuados" 35 . De esta manera, continúa, estos principios pueden entregar una guía de valores que los procesos de justicia restaurativa deberían observar.

\section{Estándares contenidos en normativa de Derechos Humanos y Justicia Restaurativa}

Braithwaite señala que muchos de los límites que la justicia tradicional considera esenciales son importantes también en los programas restaurativos, aunque muchas veces necesitan ser redefinidos $^{36}$. El autor plantea que una buena guía para fijar estos estándares son los principios contenidos en las declaraciones de derechos humanos de las Naciones Unidas. El problema, sin embargo, es que estos instrumentos no son unívocos. Cuando Braithwaite está pensando en estándares de derechos humanos para la justicia restaurativa, está pensando en algo diferente a las convencionales salvaguardas relativas al debido proceso, que son los estándares que los teóricos del 'justo merecimiento' deben tener en mente cuando critican los programas de justicia restaurativa $^{37}$. Morris, haciéndose cargo de la reiterada crítica a los programas de justicia restaurativa que sostiene que fallan en garantizar los derechos de los ofensores, señala que "Generalmente no hay nada en los valores de la justicia restaurativa que podría llevar a erosionar o negar los derechos de los ofensores... lo que hace la justicia restaurativa es fijar diferentes

Braithwaite, J. (2002) Restorative Justice and Responsive cit. nota n.9, p. 13.

Braithwaite, Setting, cit. nota n.29, p.564.

En esta línea Braithwaite distingue tres categorías de estándares para los programas de justicia restaurativa: estándares obligatorios, estándares maximizadores y estándares emergentes. Los primeros son aquellos que especifican ciertos límites y derechos y derivan básicamente de instrumentos de derechos humanos. Entre ellos se incluyen, límites máximos de sanciones, participación activa de los involucrados y los derechos básicos contenidos en declaraciones de derechos humanos. Estos estándares deberían estar siempre presentes en la implementación de estos programas. Los estándares maximizadores, que no siempre son obligatorios, pero sí deseables, incluyen entre otros restauración de la comunidad, propiedad, libertad, humanidad, etc. Braithwaite sostiene que estos estándares también pueden ser extraídos de los valores contenidos en instrumentos internacionales de derechos humanos. Por último, los estándares emergentes son valores que sin ser obligatorios, sería necesario implementar para el éxito de los programas restaurativos, como por ejemplo la censura del acto, petición de disculpas, perdón, etc. Este trabajo, sin embargo, discute sólo algunos aspectos relacionados con los estándares que podrían encuadrarse en la primera categoría, esto es, estándares obligatorios. Braithwaite, Restorative justice and Responsive, cit. nota n.9. 
Justicia restaurativa y proceso penal garantías procesales: límites y posibilidades

Restorative justice and criminal justice procedural safeguards: limits and possibilities

prioridades en la protección de los derechos de los ofensores, alejándose de un proceso donde los abogados son los protagonistas y son entrenados para minimizar la responsabilidad de su cliente y obtener la menor pena posible" 38 .

Puede argumentarse, entonces, que los instrumentos internacionales de derechos humanos pueden brindar una guía útil para establecer estándares en esta materia, no obstante, la discusión sobre cuáles estándares específicos de derechos humanos deben guiar la implementación de estos procesos y la manera en que deberían hacerlo no deja de plantear obstáculos.

En primer lugar, los estándares de derechos humanos han sido concebidos primordialmente en relación a los derechos del imputado en un contexto que sitúa al estado y al imputado como los actores principales del conflicto y en cual el objetivo del estado es condenar al imputado si se lo declara culpable. El ofensor, así, necesita un 'escudo' de garantías que lo proteja frente a la persecución estatal.

Los procesos de justicia restaurativa, sin embargo, desafían esta dinámica. El cambio de paradigma reclamado por estos programas demanda que todas las partes envueltas en el conflicto participen activamente en la resolución de éste. El estado, por supuesto, conserva un rol determinante. Por ejemplo, decide qué casos pueden ser derivados a un proceso restaurativo, supervisa la legalidad de los procesos, vela por el cumplimiento de los acuerdos y generalmente ofrece el marco legal dentro del cual estos se desarrollan. Pero la decisión de participar en un proceso restaurativo, a qué tipo de acuerdo se va a llegar (dentro de un cierto marco legal) y algunas veces incluso la forma en la cual el proceso será conducido, son decisiones de las partes, no del estado.

Como se ve, el imputado en un proceso de justicia restaurativa no está en la misma posición en que se encuentra un ofensor frente a un proceso criminal tradicional, básicamente porque el proceso restaurativo no se orienta a probar hechos, sino a establecer mecanismos de solución del conflicto y en este contexto, el ofensor tiene la posibilidad de discutir con la víctima una manera satisfactoria de hacerlo. Así las cosas, existen razones para cuestionar la pertinencia y necesidad de aplicar las mismas garantías procesales establecidas en el contexto del proceso criminal tradicional a los programas de justicia restaurativa. En otras palabras, el imputado que accede a un programa de justicia restaurativa no se encuentra en la misma posición de un imputado que está negando su participación en los hechos que se le incriminan y al cual le espera un proceso excluyente, en el cual tendrá un rol marginal y con cierta seguridad se lo condenará a una pena que puede ser privativa de libertad.

Un segundo aspecto a considerar en relación a los estándares de derechos humanos y

38 Morris, A. (2003) "Critiquing the critics: a brief response to critics of restorative justice" en Johnstone, G. (ed), A Restorative Justice Reader Texts, sources, context. Inglaterra: Willan Publishing, p.462. 
garantías procesales es que más allá de las garantías establecidas a favor de los ofensores, durante las últimas décadas se han desarrollado estándares internacionales relativos a la participación de las víctimas en el proceso criminal. Estos instrumentos, aunque generalmente no vinculantes para los estados, han puesto en evidencia la necesidad de darle voz a la víctima en el proceso, asesorarla y muchas veces entregarle protección y reparación. Dada la marginal participación que la víctima ha tenido históricamente en el proceso criminal (tanto en el proceso inquisitivo como en el acusatorio), estos estándares tienden a ser restringidos, pero aplicados a procesos restaurativos pueden ser una buena guía y la vez expandir su influencia. La justicia restaurativa, de este modo, puede constituir un mejor escenario para implementar estos estándares en relación a las víctimas, estándares que en la justicia criminal tradicional no han tenido en términos generales un impacto determinante.

Finalmente, en cuanto a la normativa internacional específicamente relativa a justicia restaurativa, un interesante, aunque de ninguna manera exhaustivo paso adelante para el establecimiento de estándares, lo constituye la declaración 'Principios Básicos sobre el uso de programas de justicia restaurativa en materia criminal' de 2002.

Esta Declaración ofrece ciertas definiciones básicas relativas a programas de justicia restaurativa y describe en términos generales la forma en que estos procesos debieran insertarse en el contexto de la justicia penal. Asimismo, promueve la expansión de estos programas y su disponibilidad durante todas las etapas del proceso. Sin embargo, esta declaración deja muchos espacios abiertos que no solucionan las contradicciones que puedan plantearse entre ésta misma y otros instrumentos de derechos humanos en la materia. Así, por ejemplo, en la cláusula 23 establece que "Nada de lo establecido en estos principios básicos afectará los derechos de los ofensores o las víctimas establecidos en la legislación nacional o internacional aplicable". Así, la declaración no avanza en enfrentar las posibles contradicciones que se pueden plantear entre sus disposiciones y otras legislaciones nacionales e internacionales, lo que deja el camino abierto al debate.

En suma, existe un número importante de instrumentos internacionales que establecen estándares y garantías para los procesos de justicia criminal. Ellos pueden ser una guía para la implementación de programas de justicia restaurativa, pero también contienen limitaciones. Como señala Van Ness "Los estándares y normas (contenidos en instrumentos internacionales de derechos humanos) reflejan diversas teorías sobre la justicia criminal que crecieron y cayeron durante la última mitad del siglo pasado, incluyendo la caída del ideal de rehabilitación en muchos países occidentales y su reemplazo por el del 'justo merecimiento', la influencia del movimiento pro-víctimas, y el surgimiento del interés por la mediación y conciliación en el proceso de justicia criminal" 39 .

39 Van Ness, D. (1996) "Restorative Justice and International Human Rights" en Galaway, B. and Hudson, J. (eds). Restorative Justice: International Perspectives. Monsey, Nueva York: Criminal Justice Press. p.20. 
Justicia restaurativa y proceso penal garantías procesales: límites y posibilidades

Restorative justice and criminal justice procedural safeguards: limits and possibilities

Es importante hacer hincapié en el hecho de que el contenido e interpretación de los estándares de derechos humanos cambian de acuerdo a las diversas tendencias políticas y teorías políticocriminales dominantes y pueden encontrarse inconsistencias entre ellos a raíz de esta situación. En este sentido, los programas de justicia restaurativa tienen el potencial de contravenir o adaptarse estándares de derechos humanos según cuál sea el estándar de que se trate.

\section{Compatibilidades e incompatibilidades entre estándares tradicionales de debido proceso y Justicia Restaurativa}

En lo que sigue se analizarán algunos aspectos problemáticos relativos al contenido de los estándares de implementación para programas de justicia restaurativa. El análisis se hará especialmente desde el punto de vista de las garantías procesales de los imputados y las compatibilidades e incompatibilidades entre las garantías requeridas por los procesos de justicia restaurativa y los procesos de justicia criminal tradicional.

¿Deben los programas de justicia restaurativa ajustarse a los mismos estándares y contemplar las mismas garantías que los procesos criminales convencionales?

Los procesos de justicia criminal, como ya señalamos anteriormente, han sido objeto de severas regulaciones y limitaciones. Entre otras, estas garantías contemplan el derecho a un juicio, a presentar evidencia, a participar en el proceso, el derecho a un tribunal independiente e imparcial establecido por ley, a audiencias públicas, a ser juzgado en un plazo razonable, el derecho a guardar silencio y a no auto inculparse, presunción de inocencia, asistencia letrada, etc. El amplio desarrollo de estos estándares, especialmente desde la segunda guerra mundial, ha sido de incuestionable valor, especialmente en lo que se refiere a limitar la arbitrariedad de los estados a la hora de ejercer el poder ${ }^{40}$. Todas las Convenciones más relevantes de derechos humanos contienen varias (y similares) garantías relativas al debido proceso y la mayoría de ellas se encuentran incorporadas en las Constituciones a nivel local.

Pero esta 'justa administración de justicia’ establecida por las Convenciones internacionales no es, sin embargo, siempre o totalmente compatible con las prácticas de justicia restaurativa. Más aún, algunas de estas garantías no son requeridas en el contexto de procesos restaurativos y algunas reglas requeridas por ellos no están contempladas en estos instrumentos internacionales. Ello, desde mi punto de vista, básicamente porque la justicia restaurativa cuestiona a la justicia criminal tradicional justamente en algunos de los aspectos que hacen

40 MacCormick, N. y Garland, D. (1998) "Sovereign States and Vengeful Victims: The Problem of the Right to Punish" en Ashworth, A. and Wasik (eds); M. Fundamentals of Sentencing Theory. Oxford, Inglaterra: Clarendon Press, p.28. 
necesario el establecimiento de las garantías procesales contenidas en los instrumentos internacionales.

En primer término, la justicia restaurativa entiende al delito, antes que nada, como un conflicto entre víctima y ofensor (generalmente también a su comunidad cercana) y no como un conflicto restringido al ofensor y el estado. En consecuencia, el ofensor no está en situación de defenderse frente a la persecución, sino que envuelto en un proceso que le ofrece la posibilidad de discutir los efectos del delito con quienes han sido afectados por éste, con el objeto de arribar a la mejor solución para todos los involucrados.

En segundo lugar, los procesos restaurativos no son un proceso de averiguación de los hechos, como la justicia convencional. Los programas de justicia restaurativa, en cambio, se orientan a determinar qué pasa luego de que una persona ha admitido que ha cometido una ofensa criminal, o no ha negado su responsabilidad, según sea el caso. El proceso no busca establecer si los hechos ocurrieron o no. Se ocupa, en cambio, en determinar qué debe hacerse luego de que la persona ha admitido algún grado de responsabilidad. En este contexto, muchas de las garantías tradicionales pierden su fundamento.

Finalmente, el consentimiento del ofensor para participar en un programa restaurativo es siempre un requisito de procedencia. De esta manera, el estado tiene menos incentivos para usar la fuerza en su contra, por lo tanto, los riesgos de abuso, que justifican la implementación de ciertas garantías, disminuyen.

En adelante se analizan algunas de las garantías básicas del debido proceso a la luz de la dinámica de los programas de justicia restaurativa, con el objeto de indagar de una manera más específica en las posibilidades y limitaciones que éstas ofrecen en el contexto de los procesos restaurativos.

\section{Derecho a un juicio justo y público ante un tribunal independiente e imparcial}

Tanto el Convenio Europeo para la protección de los Derechos Humanos y las Libertades Fundamentales, como la Convención Internacional de Derechos Civiles y Políticos y la Convención Americana sobre Derechos Humanos ${ }^{41}$ establecen el derecho a un juicio justo ante un tribunal independiente e imparcial. Este derecho incluye tres diferentes aspectos: derecho a ser oído, por un tribunal independiente y por un tribunal imparcial. Veremos cada uno de estos aspectos por separado.

$41 \quad$ Esta última, en el Artículo 8.1 
Justicia restaurativa y proceso penal garantías procesales: límites y posibilidades

Restorative justice and criminal justice procedural safeguards: limits and possibilities

\section{Derecho a ser oído}

Los programas de justicia restaurativa han sido criticados por contravenir el derecho ser oído en un juicio público, pues las conferencias, los programas de mediación, o cualquiera sea el programa restaurativo de que se trate, no constituyen una audiencia pública ante un tribunal. Sin embargo, esta crítica parece ser infundada. Como señalan los instrumentos internacionales anteriormente citados, el ofensor tiene el derecho a ser oído por un tribunal que reúne determinadas condiciones. El ofensor, por lo tanto, tiene un derecho, pero, tal como lo señala el Consejo de Europa en su Recomendación (99)19, bajo ciertas circunstancias este puede optar por un proceso diferente si así lo estima necesario.

El derecho a ser oído, tal como lo señala la jurisprudencia de la Corte Europea de Derechos Humanos en el caso 'Deweer' 42 , no es un derecho absoluto y puede estar sujeto a limitaciones en determinadas circunstancias. De hecho, la decisión de no seguir adelante con la investigación es un ejemplo de ello. El fallo señala además que el derecho a ser oído puede ser desestimado por las partes, siempre que esta desestimación sea suficientemente cautelada. Para la Corte "Una desestimación que es innegablemente ventajosa para los individuos involucrados y para la administración de justicia, no ofende en principio a la Convención" ${ }^{43}$.

De lo que se trata entonces es determinar cuándo puede considerarse que la desestimación ha sido efectuada en circunstancias adecuadas. El punto crucial, sin duda, es establecer si el ofensor renunció a su derecho a un juicio y accedió a participar en un programa restaurativo de forma libre, sin coerción. Este aspecto se analiza con detalle más adelante.

\section{Derecho a un tribunal independiente e imparcial}

Ashworth ${ }^{44}$ ha señalado que una conferencia o un círculo no asegura el estándar básico a ser oído por un tribunal independiente e imparcial establecido en la Convención Europea, pues en tanto la víctima tiene un rol activo en la determinación del acuerdo, el 'tribunal' no podría considerarse como independiente, por lo tanto se pasa a llevar el estándar establecido por ésta. Al mismo tiempo, dado que las víctimas no hablan en nombre del tribunal y no están informadas sobre todas las alternativas legales disponibles sobre el caso, están lejos de ser un tribunal imparcial.

Corte Europea de Derechos Humanos, 27.02.1980, Series A Nº35.

Caso Deweer, Párrafo 49.

Ashworth, A. (2003) "Is Restorative Justice the Way Forward for Criminal Justice?" en McLaughlin, E., Fergusson, R., Hughes, G., and Westmarland, L. (eds.) Restorative Justice. Critical Issues. Londres: Sage Publications. p.171. 
Ashworth, en el mismo artículo, anticipa la respuesta a su cuestionamiento: su argumento asume que los requerimientos de la justicia moderna son correctos, pero la verdad es que estos dejan muchas preguntas sin responder y son históricamente defectuosos. Para Ashworth, sin embargo, esta respuesta no es suficiente, pues considera que el 'debate de principios' debe ser correctamente abordado. De esta manera, "La imparcialidad e independencia deben ser estándares básicos del proceso de justicia criminal, particularmente a la hora de la decisión y el involucramiento de la víctima en el proceso de toma de decisiones pone una carga en el ofensor que parece ser incompatible con estos estándares" ${ }^{45}$.

Se puede coincidir con Ashworth en la necesidad de confrontar el asunto de principios, especialmente cuando los principios están contenidos en tratados internacionales de carácter vinculante. Sin embargo, se puede intentar otra respuesta a su argumento también desde los principios. Así, lo que estos instrumentos demandan no es precisamente un tribunal independiente e imparcial para todos. Lo que demandan es el derecho a un juicio ante un tribunal independiente e imparcial. Dado que, como se vio anteriormente, el derecho a ser oído ante un tribunal puede ser desestimado por las partes involucradas, un procedimiento restaurativo no contraviene necesariamente este derecho. Es evidente que la víctima en un proceso criminal no es independiente ni imparcial, tal como tampoco lo es el ofensor. Por definición no son independientes ni imparciales, pues son las partes involucradas en el conflicto objeto de decisión. Ashworth señala que si la víctima toma parte en el proceso de toma de decisiones el 'tribunal no es independiente', pero parece desconocer que una conferencia restaurativa no es un tribunal ni pretende serlo. De hecho, en muchos aspectos es la antítesis de un tribunal y por lo mismo no se espera que sea independiente o imparcial.

En la misma línea de Ashworth et al. ${ }^{46}$ señalan que en una conferencia restaurativa, dos de los principales participantes, víctima y ofensor, son claramente parciales. Los autores agregan que podría argumentarse que la imparcialidad no es un problema cuando la sanción no es impuesta externamente, por un juez, sino que negociada por los afectados por la ofensa. Sin embargo, sostienen que el problema permanece pues aunque el ofensor puede desistir del proceso en el momento que estime conveniente, por ejemplo si siente que no está siendo tratado justamente, la viabilidad de abandonar el caso, sin embargo, depende de qué alternativas al proceso le aguardan. Él puede tener razones para sentir que debe aceptar un determinado proceso por temor de enfrentar algo peor. La falta de imparcialidad, entonces, sigue siendo un inconveniente.

\footnotetext{
$45 \quad$ Idem

46 Von Hirsch, A., Ashworth, A., Shearing, C. (2003) "Specifying Aims and Limits for Restorative Justice: A 'Making Amends' Model?'” en Restorative Justice and Criminal Justice. Competing or Reconcilable Paradigms? Von Hirsch, A., Roberts, J., Bottoms, A., Roach, K., Schiff, M (eds) Oxford, Inglaterra: Hart Publushing. p. 32.
} 
Justicia restaurativa y proceso penal garantías procesales: límites y posibilidades

Restorative justice and criminal justice procedural safeguards: limits and possibilities

Pero, nuevamente, el problema dice relación con la forma de garantizar la legitimidad del desistimiento y no con la independencia o imparcialidad. Si existe acuerdo en el hecho de que el ofensor puede renunciar a su derecho a ir a un juicio y optar por un procedimiento alternativo, debería existir acuerdo, también, en que ese proceso alternativo no debiera cumplir los mismos requisitos de independencia e imparcialidad, simplemente porque no es un tribunal. Así, la verdadera pregunta que debe responderse es una pregunta anterior, esto es, si se está de acuerdo o no con permitir un procedimiento alternativo dentro del sistema penal. Si la respuesta es afirmativa, estos procedimientos deben regularse y limitarse, pero debe hacerse de manera tal que el procedimiento pueda cumplir con sus objetivos. Si la respuesta es negativa, no deben permitirse como alternativa en el sistema. Pero lo que no se puede hacer es implementar nuevas vías de solución de conflictos, como las conferencias restaurativas, para luego juzgar su legalidad y legitimidad de acuerdo a estándares que están pensados para proteger los derechos del ofensor en un contexto completamente diferente.

Un estándar que sí debería estar presente en la implementación de cualquier programa de justicia restaurativa, de acuerdo a lo señalado anteriormente, es la participación libre y voluntaria del ofensor en el procedimiento. El ofensor, además, debe siempre tener la posibilidad de abandonar este procedimiento y volver al tradicional si lo estima conveniente. La filosofía que subyace a estos programas indica que la participación activa del ofensor en el proceso es clave. Uno de los objetivos más importantes del procedimiento es que el ofensor acepte su responsabilidad en el delito, idealmente se disculpe y se elabore un plan para reparar y superar la situación. De hecho, investigaciones han demostrado que cuando el ofensor se disculpa sinceramente en una conferencia restaurativa, es menos probable que reincida en el futuro ${ }^{47}$. En este contexto, un ofensor reacio a participar tiene poco que hacer en un proceso restaurativo. El consentimiento, por tanto, debe ser libre.

Se ha argumentado ${ }^{48}$ que la amenaza de una persecución criminal por el sistema convencional es suficiente para considerar que el ofensor no ha aceptado voluntariamente el proceso restaurativo. Sin embargo, como ha argumentado la Corte Europea de Derechos Humanos en el caso Deweer, la amenaza de una persecución criminal no constituye, en principio, coerción suficiente para el ofensor ${ }^{49}$. De acuerdo al razonamiento de la Corte, sólo podría haber coacción cuando hay una flagrante desproporción entre las dos alternativas. Veamos entonces si la justicia restaurativa puede considerarse desproporcionadamente más blanda que la justicia tradicional.

47 Morris, A. y Young, W. (2000) "Reforming Criminal Justice: The Potential of Restorative Justice" en Strang, H., y Braithwaite, J. Restorative Justice. Philosophy to Practice. Aldershot: Ashgate. p.19.

48 Levrant, S., Cullen, F., Fulton, B., y Wozniak, J. (2003) "Reconsidering restorative justice: the corruption of benevolence revisited?" en Johnstone, G. (ed.) A Restorative Justice Reader. Texts, sources, context. Inglaterra : Willan Publishing. p.418.

49

Caso Deweer, párrafo 51 (a) 
Gran parte de la literatura sobre justicia restaurativa argumentaría que no es así. Estos programas buscan resolver los conflictos generados por el delito de una manera significativa y humana, pero no necesariamente más suave. Basta tener presente que en un encuentro restaurativo el ofensor debe enfrentar cara a cara a la víctima del delito, lo que muchas veces es extremadamente difícil y además se compromete a reparar de una manera significativa los perjuicios causados. Pero incluso aunque se pensara que sí hay una desproporción flagrante entre ambos procedimientos, lo que daría indicios de coacción ¿cuál sería la solución correcta? Existen varias alternativas: considerar que el consentimiento no es válido, porque no es libre y por lo tanto no se deberían permitir los procedimientos restaurativos por esta razón; endurecer los procesos restaurativos, en orden a hacerlos más proporcionales; o bien, humanizar el proceso criminal tradicional. Personalmente me inclino por la última alternativa.

Pero más allá de esta discusión de principios, en la práctica y especialmente cuando se trata de ofensores menores de edad o que por alguna razón están en una situación de debilidad, enfrentados al estrés de un proceso criminal y ante la posibilidad de ser condenados, pueden sentir que no hay otra opción más que aceptar el procedimiento alternativo. La evaluación del programa piloto de implementación de la nueva regulación de justicia juvenil en Irlanda del Norte mostró que un cuarto de los jóvenes ofensores manifestaron que accedieron al plan acordado, "no porque quisieran, sino porque sentían que debían hacerlo" 50 . Por esta razón, se debe poner énfasis en este punto y asegurar, en la medida de lo posible, la voluntariedad para acceder a todas las etapas y aspectos del procedimiento. Una manera de asegurarlo es proveer un adecuado asesoramiento legal antes de acceder a participar, especialmente para asegurar que una persona inocente no se declare culpable por temor a lo que deberá enfrentar en el futuro proceso penal.

Ahora bien, la imparcialidad puede tener un espacio en los programas restaurativos, pero desde una perspectiva diferente que la de un 'tribunal imparcial'. Así, es común encontrar que estos programas demandan la imparcialidad del mediador, coordinador, o quien sea que dirija el proceso restaurativo. Así, por ejemplo, la Recomendación (99)19 del Consejo de Europa señala que el mediador no debe tomar partido, sino que debe permitir que las partes se expresen libremente y lleguen a un acuerdo. La exigencia de imparcialidad, sin embargo, no significa que quien esté a cargo del programa sea indiferente al hecho de que se ha cometido un delito. Como se señala en el párrafo 16 de la Recomendación, "Las partes en una mediación penal, están, entonces, a diferencia de una mediación civil, en una posición desigual, con la mayor parte de las obligaciones del lado del ofensor. Sin embargo, de acuerdo al principio de presunción de inocencia, el mediador no debe tomar posición sobre el asunto de la culpabilidad".

50 Beckett, H, O’Mahony, D, Doak, J, Campbell, C y Jackson, J (2004). Interim Evaluation of the Northern Ireland Youth Conferencing Scheme. Research and Statistical Bulletin 1/2005. Belfast: Northern Ireland Office, Statistics and Research Branch. p.11. 
Justicia restaurativa y proceso penal garantías procesales: límites y posibilidades

Restorative justice and criminal justice procedural safeguards: limits and possibilities

Más aún, el facilitador debe ser capaz de enfrentar los desequilibrios de poder entre los participantes. Una crítica reiterada en contra de estos programas (especialmente cuando se trata de violencia de género o racial) es que no serían capaces de confrontar estos desequilibrios y por tanto las partes más débiles pueden resultar dañadas como consecuencia del procedimiento. No obstante, la experiencia muestra que estas desigualdades pueden ser abordadas en el proceso restaurativo. Como señala Stubbs, refiriéndose al caso de Nueva Zelanda "Los desequilibrios de poder pueden ser abordados en un programa de justicia restaurativa asegurando la equidad, apoyando al más débil y desafiando al más poderoso... La justicia restaurativa tiene el potencial de desafiar las normas y valores comunitarios que justifican la violencia del hombre en contra de sus parejas" ${ }^{51}$.

Finalmente, como señala Morris $^{52}$, se puede argumentar que reducir los desequilibrios de poder es un objetivo que la justicia tradicional ni pretende ni logra.

\section{Presunción de inocencia}

También relacionada con el asunto del consentimiento se encuentra la garantía de presunción de inocencia. La Convención Americana sobre Derechos Humanos ${ }^{53}$ señala que "Toda persona inculpada de delito tiene derecho a que se presuma su inocencia mientras no se establezca legalmente su culpabilidad".

El primer aspecto relacionado con la presunción de inocencia y los programas de justicia restaurativa dice relación con el requisito de entrada a estos programas. Esto es, que todas las partes deben aceptar los hechos fundamentales de la imputación y por regla general, que el ofensor acepte su responsabilidad ${ }^{54}$.

La presunción de inocencia tiene al menos dos acepciones. Por una parte, garantiza que la culpabilidad debe ser probada más allá de toda duda razonable. Este aspecto de la presunción de inocencia, a la vez, tiene dos sentidos. En primer término, la carga de la prueba está en la persecución (la fiscalía) En segundo lugar, establece un estándar de prueba (más allá de toda duda razonable) Por otra parte, esta garantía impone que el ofensor, durante el proceso, debe

$51 \quad$ Stubbs, J. (2004) "Restorative Justice, Domestic Violence and Family Violence”, Australian Domestic \& Family Violence. Issues paper 9. p.11.

52 Morris, Critiquing, cit. nota n.40, p.467.

53 Art. 8.2. En similares términos el Convenio Europeo para la protección de los Derechos Humanos y las Libertades Fundamentales, Art. 6.2.

54 Los Principios Básicos (2002) señalan que 'La víctima y el ofensor deberían coincidir en los hechos básicos del caso para participar en un proceso restaurativo.' 
ser tratado como si fuera inocente, esto es, reduciendo al máximo el detrimento de sus derechos durante el proceso ${ }^{55}$.

¿Qué es lo que ocurre en un procedimiento restaurativo? Es cierto que el ofensor debe admitir responsabilidad en los hechos del caso, pero esto no es lo mismo que declarase culpable ante el sistema de justicia penal. Así, si el proceso restaurativo es exitoso, la presunción de inocencia no se ve afectada, porque el ofensor accedió voluntariamente y nunca fue considerado 'culpable' en el proceso. El ofensor decidió desestimar su derecho a un juicio donde podría haber sido considerado inocente para efectos de defenderse de la acusación fiscal. En la conferencia el ofensor acepta los hechos de la imputación, no niega los cargos, o los acepta y accede a una forma de reparación, de manera que el hecho de la 'culpabilidad' pierde relevancia.

Una situación más problemática se presenta cuando el proceso restaurativo falla. En este caso, la participación del ofensor en el procedimiento alternativo podría ser vista como una aceptación de culpabilidad y por lo tanto ser usada en su contra en el subsecuente proceso penal. Sin embargo, los procesos restaurativos generalmente contienen (o deben contener) resguardos frente a ello. Tanto los Principios Básicos (2002) como la Recomendación (99)19 se anticipan al problema y establecen que la participación en estos programas no puede ser usada como evidencia de culpabilidad en un proceso posterior (algo similar a lo que ocurre en el Código Procesal Penal chileno con la Suspensión Condicional del Procedimiento y los Acuerdos Reparatorios)

Finalmente, como señaláramos, la garantía de presunción de inocencia implica además que el imputado debe ser tratado como inocente durante el proceso, en orden a prevenir abusos. Los programas de justicia restaurativa cumplen, sin lugar a dudas y de mejor manera que el procedimiento convencional, con este requisito.

\section{Derecho a asistencia legal}

La Convención Americana sobre Derechos Humanos establece en el artículo 8.2 d) el "derecho del inculpado a de defenderse personalmente o de ser asistido por un defensor de su elección y de comunicarse libre y privadamente con su defensor" y en la letra e) el "derecho irrenunciable de ser asistido por un defensor proporcionado por el Estado, remunerado o no

Riego, C. (1996) "El sistema procesal penal chileno frente a las normas internacionales de derechos humanos" en Medina, C y Mera, J., (eds.), Sistema Jurídico y Derechos Humanos. El derecho nacional y las obligaciones internacionales de Chile en materia de Derechos Humanos. Santiago, Chile: Serie publicaciones especiales, N6, Escuela de Derecho Universidad Diego Portales. p.314. 
Justicia restaurativa y proceso penal garantías procesales: límites y posibilidades

Restorative justice and criminal justice procedural safeguards: limits and possibilities

según la legislación interna, si el inculpado no se defendiere por sí mismo ni nombrare defensor dentro del plazo establecido por la ley"56.

La participación de abogados en el marco de los programas de justicia restaurativa es un asunto complejo. Por ejemplo, en Australia y Nueva Zelanda la oposición más fuerte a estos programas ha venido desde los abogados ${ }^{57}$. Esto, básicamente, porque el rol que cumplen estos en un proceso tradicional se opone a los postulados de la justicia restaurativa. Como señala Braithwaite "En ninguna jurisdicción parece ser apropiado que los ofensores tengan el derecho a que los represente un abogado durante un proceso de justicia restaurativa. Parte de la idea de la justicia restaurativa es trascender el legalismo adversarial y alentar a los interesados a hablar por sí mismos en vez de hacerlo a través de un portavoz que pueda tener interés en polarizar el conflicto... Esto no significa que deba prohibirse la intervención de abogados bajo cualquier circunstancia... donde los abogados firmen un acuerdo de colaboración y sean especialmente entrenados en valores y técnicas de colaboración, podría haber un especial interés en escuchar sus apreciaciones" $" 58$.

Dentro de los valores más importantes de la justicia restaurativa se encuentra la posibilidad de que todos los involucrados discutan personalmente sobre la forma de superar el conflicto. El rol de un abogado en un proceso penal es representar los intereses de su cliente y así hablar por él y elaborar la mejor estrategia para resolver el caso. Ninguna de estas intervenciones es bienvenida en un programa restaurativo. Pero ello, como se ha dicho anteriormente, no significa que los abogados no puedan tener un interesante rol que cumplir en este ámbito. Lo que ocurre es que se espera algo diferente.

Los Principios Básicos (párrafo 13) señalan que la víctima y el ofensor deberían contar con una asesoría legal en lo referido a su participación en un programa restaurativo. Así, antes de acceder a participar en uno de estos procesos, las partes deben estar plenamente informadas de sus derechos, de la naturaleza del proceso y de las consecuencias que pueden acarrear sus decisiones.

En el caso de las $F G C$ de Nueva Zelanda los facilitadores pueden requerir la presencia de algún abogado (pagado por el estado) si tienen alguna preocupación por los derechos de los jóvenes ofensores. Además, cuando el joven es derivado a una conferencia a través de la Corte, generalmente en los casos más graves, pueden contar con la presencia de su abogado durante la Conferencia ${ }^{59}$. En el caso de Irlanda del Norte, los jóvenes infractores también pueden

En términos similares, el Convenio Europeo para la protección de los Derechos Humanos y las Libertades Fundamentales, Art. 6,3c.

57 Braithwaite, Restorative Justice and Responsive, cit. nota.9, p.565.

$58 \quad$ Idem pp. $566-567$

$59 \quad$ Morris, A. Critiquing, cit. nota n.40, p.462. 
contar con esa asesoría, pero como señalan O’Mahony y Campbell, el abogado sólo puede participar como asesor y no puede reemplazar la participación directa del joven en la conferencia ${ }^{60}$.

En síntesis, la asistencia legal es bienvenida y muchas veces requerida en los programas restaurativos con el objeto de asegurar que los derechos del ofensor sean respetados. Por esta razón y especialmente en casos de especial vulnerabilidad, el ofensor debería contar con la asesoría de un abogado antes de decidir su participación en el procedimiento. Más aún, debería siempre contarse con la opinión de un abogado cuando el acuerdo restaurativo parece a simple vista desproporcionado o se levantan dudas sobre el respeto de los derechos del imputado. Sin embargo, deben tomarse los resguardos necesarios para asegurar que la asistencia legal no signifique marginalizar la participación del ofensor en el proceso, como ocurre en un proceso criminal tradicional. Por último, los abogados que tomen parte en estos procedimientos deberían contar con una capacitación especial acerca de los principios y funcionamiento de los programas de justicia restaurativa, para poder entregar una asesoría legal adecuada.

\section{Conclusión}

El movimiento de justicia restaurativa ha reclamado que representa un 'nuevo paradigma' de justicia, un cambio frente al sistema tradicional. En términos prácticos, sin embargo, sólo ha logrado instalarse como una alternativa real al procedimiento tradicional en contadas jurisdicciones (como es el caso de los sistemas penales juveniles de Nueva Zelanda e Irlanda del Norte) En muchas otras, por su parte, los programas restaurativos representan una alternativa más o menos reducida, dentro del modelo de justicia penal tradicional, aunque en expansión.

Como los procesos de justicia criminal han sido tradicionalmente objeto de innumerables regulaciones, tanto a nivel nacional como internacional, la emergencia de estos programas, especialmente cuando aspiran a ocupar un lugar de mayor relevancia, abren el espacio al debate sobre su regulación. En otras palabras ¿son compatibles los programas de justicia restaurativa con los estándares clásicos relativos al proceso penal? Como se ha visto, existen fundamentos para considerar que los programas de justicia restaurativa no deben cumplir con todos los estándares tradicionales y además muchas veces es necesaria la inclusión de nuevos estándares o la reformulación de otros. Ello, básicamente porque al contrario de la justicia tradicional, que se ve obligada a entregar un escudo de protección frente a la persecución estatal a todo aquél imputado de delito, los programas de justicia restaurativa presentan un escenario incluyente, en el cual las partes participan de manera voluntaria en orden a consensuar vías adecuadas de resolución de los conflictos.

O’Mahoney, D. y Campbell, C. (2004) “Mainstreaming Restorative Justice for Young Offenders through Youth Conferencing- the experience of Northern Ireland.' http://www.esc-eurocrim.org/files/northernireland report.doc. p.10. (visitado 12.09.08). 
Justicia restaurativa y proceso penal garantías procesales: límites y posibilidades

Restorative justice and criminal justice procedural safeguards: limits and possibilities

La justicia restaurativa es parte del sistema de justicia criminal y como tal debe contemplar regulaciones para no afectar los derechos de los involucrados. Sin embargo, como estos programas intentan romper el esquema tradicional 'estado versus imputado', los estándares tradicionales no siempre cumplen con la función que los justifica, esto es, permitir desarrollar el proceso de manera efectiva, sin vulnerar derechos. Como se ha visto, las garantías tradicionales de debido proceso establecen derechos para los imputaos que son fundamentales y que se justifican en la dinámica del proceso criminal tradicional. Al incorporar procedimientos restaurativos como mecanismos de solución de conflictos penales se hace necesario revisar el contenido de estas garantías. No se trata, como se ha visto, de negar derechos a los imputados. Lo que se plantea es que un análisis serio y acabado se debe llevar adelante sobre las compatibilidades e incompatibilidades de los estándares tradicionales frente a los procesos restaurativos. Este trabajo intenta dar un paso adelante en este sentido, esto es, analizar la justificación y sentido de ciertas garantías en el proceso tradicional y confrontarlas con el sentido y justificación que ellas podrían tener en un proceso restaurativo. En mi opinión, es posible compatibilizar muchas de las garantías tradicionales del debido proceso con los requerimientos de la justicia restaurativa, una vez que se toma en cuenta el objetivo que éstas persiguen. Así, por ejemplo, se argumentó que la justicia restaurativa es compatible con un tribunal independiente e imparcial, pues este tribunal es un derecho al que el imputado debería acceder en toda etapa del proceso de no querer aceptar o continuar un proceso restaurativo. No sería legítimo argumentar, sin embargo, que un proceso restaurativo vulnera la garantía de un tribunal independiente e imparcial porque una mediación o conferencia 'no es un tribunal independiente o imparcial', pues no lo es, ni pretende serlo. Justamente es un procedimiento diverso que se plantea como alternativa a un tribunal, para resolver los conflictos de una manera más participativa y por lo tanto, requiere del involucramiento de las partes afectadas en la resolución del proceso.

La tarea de fijar estándares para estos programas es muy relevante, pero a la vez conlleva riesgos, especialmente por el corto tiempo que estos llevan implementándose y por la flexibilidad que estos requieren en orden a lograr sus objetivos. Sin embargo, el crecimiento de este movimiento hacia la resolución de delitos más graves hace esta discusión indispensable.

Los procedimientos restaurativos han sido positivamente evaluados, especialmente en legislaciones que los contemplan como una parte central de su política criminal. La tarea de fijar estándares para estos programas debe tomar en cuenta esta información. Tal vez no sea verdad que la justicia restaurativa tiene 'algo bueno para todos', sin embargo parece ser cierto que muchas veces tiene 'algo mejor' para ofensores y víctimas que la justicia tradicional. Si esto es cierto, estos programas deben ser estimulados, pero también adecuadamente regulados. Esta regulación, sin embargo, debe estar en sintonía con la filosofía que está en la base de los programas restaurativos y de esta manera le permita lograr sus objetivos. 